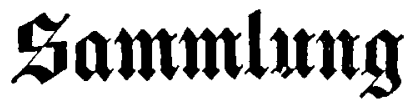

bet

fúr das

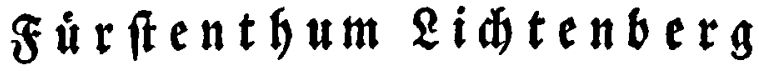
bom Jặe 1816 bís 1834

ergangenen

Shergoglich Sadfjen = Coburg = Sothaifhen

$\mathfrak{B} \mathfrak{P} \mathfrak{x} \mathfrak{D} \mathfrak{d} \mathfrak{n} \mathfrak{u} \mathfrak{g} \mathfrak{e} \mathfrak{n}$.

Mit bober Genebmigung.

Bon

F. 2 . $\operatorname{Rot} \in \mathbb{t} \in \mathrm{r}$, SInigl. Juftijtath.

\section{Berlin, 1836.}

Sanderfac badbanolung.

(C. $\mathfrak{x}$. (Etch) off.) 
